\title{
Strategies to improve the quality of midwifery care and developing midwife-centered care in Iran: Analyzing the attitudes of midwifery experts
}

\section{Shahla Khosravy}

Tehran University: University of Tehran

\section{Farah Babaey}

Ministry of Health

Parvin Abedi ( $\sim$ parvinabedi@ymail.com )

Ahvaz Jondishapour University of Medical Sciences https://orcid.org/0000-0002-6980-0693

\section{Zohreh Mazaheri Kalahroodi}

Iran University of Medical Sciences and Health Services: Tehran University of Medical Sciences

\section{Saeideh Sadat Hajimirzaie}

Shahroud University of Medical Sciences: Shahrood University of Medical Sciences

\section{Research}

Keywords: midwifery care, qualitative study, women's health, quality

Posted Date: September 8th, 2020

DOl: https://doi.org/10.21203/rs.3.rs-68394/v1

License: (c) (i) This work is licensed under a Creative Commons Attribution 4.0 International License.

Read Full License

Version of Record: A version of this preprint was published at BMC Pregnancy and Childbirth on January 16th, 2022. See the published version at https://doi.org/10.1186/s12884-022-04379-7. 


\section{Abstract}

Background: This study was conducted to provide strategies for improving the quality of midwifery care and developing midwife-centered care in Iran.

Methods: A qualitative study using the content analysis method was conducted. Data were collected from 121 participants, including midwifery board members, gynecologists, head of midwifery departments, midwifery students, in charge midwives in the hospitals, and midwives in the private sector in order to find the best strategies for improving the quality of midwifery care and developing midwifecentered care in Iran. Focused-group discussions were used for data gathering, and data were analyzed using content analysis method.

Results: The main strategies that participants mentioned for improving the quality of midwifery care were as follow: education, manpower, incentive and support system, midwifery care and duties, equipment and facilities, policy making, monitoring and interdisciplinary activities.

Conclusion: Authorities and policymakers may set the stage for developing high quality and affordable midwifery care by relying on the strategies presented in this study.

\section{Background}

Maternal and child health is especially prioritized in every society due to its direct effect on community development, so governments and societies pay special attention to the health of mother and baby (1). The importance of maternal and child health is so paramount that the World Health Organization (WHO) in its report in 2020 has particularly emphasized the concept of development of the health of mother and baby (2). Among the various groups, midwives have the best chance to provide the best care for promoting maternal and child health (3). Most women receiving midwifery care are so young that they need midwifery care in various health areas (4). In midwifery care services, a large number of women are continuously in touch with midwives, which makes early detection of mothers with certain needs easier (5).

Annually, about 600,000 women die around the world due to the consequences of pregnancy and childbearing. In addition, many women who survive suffer from the negative consequences of childbearing and pregnancy and may experience long-term disabilities. About 99 percent of these deaths and disabilities occur in countries with average or low income (5). In developed countries, however, due to the high quality and free midwifery care, the shining role of midwives in maternity care and better supervision of referral system have resulted in lower maternal mortality rate compared with developing and undeveloped countries (6-7).

The results of previous studies confirm that babies who are born from mothers without antenatal care are almost more exposed to death and childbearing consequences compared to those who are born from mothers with good antenatal and midwifery care (8). According to the WHO report, in areas where more 
than $75 \%$ of birth are performed by midwives, there is a lower rate of maternal mortality, and this rate has even decreased by $75 \%$ in the areas where employed educated midwives provide care (9).

A study on the childbirth centers in Australia showed that the antenatal death rate in these centers was less than hospital units for healthy pregnant women (10). Another study showed that women who had women centered care by midwives in pregnancies and deliveries had pleasant and good experience in childbearing with lower complications compared to medical-oriented care services for healthy women (11). In Germany, a study showed that epidural anesthesia and episiotomy rate were lower and the second stage of labor was shorted in women who received midwifery-led care in comparison to obstetrician care (12).

The results of many studies in Iran show that midwifery care is not given as much value as it is in other countries. Despite the high level of Iranian midwifery education, women do not receive proper midwifery care. One of the underlying causes for this is lack of insurance coverage for midwifery care, making women opt for a gynecologist's service that has full insurance coverage. Gynecologists, more often than not, tend to have some unnecessary interventions in antenatal care and during childbearing, which may increase the rate of caesarean Sect. (13-14). Thus, the way to reduce maternal mortalities and disabilities is to prevent those caused by unnecessary intervention during childbirth through improving the pre-birth service centers and providing high quality and accessible services for pregnant women (1516).

In the meantime, the midwifery staff has a heavy-duty in maintaining the health of mothers. Given the fact that midwives play a significantly critical role in providing primary care for saving mothers' life, it is necessary to improve the quality of midwifery care. In recent years, in developed countries, widespread studies have been designed and performed in the context of providing midwifery care, which has been unfortunately neglected in some underdeveloped and developing countries such as Iran (17-18). Hence, the purpose of the current study was to identify the main strategies for improving the quality of midwifery services and developing the midwife-centered care in Iran.

\section{Methods}

This is a qualitative study using a content analysis approach. It was designed and conducted with the aim of determining the strategies for improving the quality of midwifery services in Iran. The reason for adopting qualitative research method is the ability and capability of such type of studies in achieving indepth thoughts of participants and obtaining the silent experiences, knowledge, and information individuals.

Participants of the present study included 121 individuals from various positions as follows:

- Midwifery board members, a group of 11 people

- Gynecologists: a group of five people

- Head of midwifery departments of medical universities: five groups of six people each $(n=30)$ 
- Midwifery students: three groups of five people each $(n=15)$

- Charge midwives in university hospitals: three groups of five people each $(n=15)$

- Charge midwives of non-university hospitals: three groups of five people each (15 people)

- Head of midwifery departments of private universities (Islamic Azad Universities) of Tehran province: a group of five people

- Medical council and licensed midwives; four groups, including five people each $(n=20)$

- Charge midwives in the headquarters of Ministry of Health and Medical Education: a group of five people

Participants were selected due to their high experience and enough knowledge in their work and midwifery services in Iran.

The inclusion criteria included familiarity with midwifery services, having at least one year of work experience in midwifery and gynecology services or two years of education in the midwifery field, voluntary participation in group discussions, ability to communicate, and providing comments.

The purposive sampling method was used for selecting the participants. In this method, people are chosen as participants who have the most and richest information. The sampling continued until data saturation. In the current study, saturation was obtained with 110 participants. However, to ensure complete saturation, the researchers continued participant selection up to 121 persons. Moreover, the attempt was made to select a variety of participants in terms of age, working place, employment condition, work experience, educational degree, and occupational position to increase variety of data.

Focus group discussions were used for data collection. The group discussions were held in the midwifery office of the Health Minister Advisor in midwifery affairs and Akbar Abadi Hospital in Tehran. All participants were invited with prior coordination and formal invitation letters. Each group discussion was consisting of 5-6 people and lasted between 45 to $90 \mathrm{~min}$. At the beginning of the discussion, after introducing the interviewers, they started the discussion by asking about the status of midwifery at services at the hospital or training center. The participants' speech was recorded upon their consent, using a voice recorder while the interviewer was also taking notes in the time of group discussions. All interviews were listened to and carefully transcribed.

To analyze the data, we used content analysis, which is a method of identifying, analyzing, and reporting the patterns (themes) existing within the text and is very applicable in analyzing qualitative data (19). Data coding was done by two of the researchers. The analyses and coding stages were as follows:

Content-analysis was used to analyze the data, which in this method, identifying, analyzing, and reporting the themes are used that is very useful method in qualitative data analysis (20). The data were coded by two of the researchers. The steps of data analysis and coding were as follows: familiarity with the data text (reading the implemented texts several times - data immersion), identification and extraction of primary codes (identification and extraction of data related to the original codes), identification themes 
(inserting the extracted source code in related themes), reviewing and completing the identified themes, naming and defining the themes, ensuring the reliability of the extracted codes and themes (reaching an agreement between the two coders through discussion). Peer check and immersed data were used for data consistency.

To comply with the ethical issues in this study, we obtained informed consent from the participants and they also had the right to withdraw from the study whenever they wanted. In addition, the research purposes were explained for the participants at the beginning of the study.

\section{Results}

In this study 121 professionals participated and all participants had experiences of working in different fields of midwifery and being involved with the research topic. The details of the participants are shown in Table 1.

Table 1

Characteristics of participants in the study

\begin{tabular}{|c|c|c|c|c|c|}
\hline $\begin{array}{l}\text { Kind of professional } \\
\text { activity }\end{array}$ & $\begin{array}{l}\text { Number in } \\
\text { focus group } \\
\text { discussion }\end{array}$ & $\begin{array}{l}\text { Number } \\
\text { in each } \\
\text { group }\end{array}$ & Education & $\begin{array}{l}\text { Age } \\
\text { range } \\
\text { (v) }\end{array}$ & $\begin{array}{l}\text { Average } \\
\text { years in the } \\
\text { profession }\end{array}$ \\
\hline Midwifery board member & 1 & 11 & $\begin{array}{l}\text { Master degree } \\
\text { and } \mathrm{PhD}\end{array}$ & $\begin{array}{l}34- \\
58\end{array}$ & 19 \\
\hline Gynecologist & 1 & 5 & $\begin{array}{l}\text { Clinical } \\
\text { specialist }\end{array}$ & $\begin{array}{l}38- \\
57\end{array}$ & 20 \\
\hline $\begin{array}{l}\text { Head of midwifery } \\
\text { department }\end{array}$ & 5 & 6 & $\begin{array}{l}\text { Master degree } \\
\text { and PhD }\end{array}$ & $\begin{array}{l}30- \\
52\end{array}$ & 16 \\
\hline $\begin{array}{l}\text { In charge midwives in the } \\
\text { educational hospitals }\end{array}$ & 3 & 5 & $\begin{array}{l}\text { Master degree } \\
\text { and PhD }\end{array}$ & $\begin{array}{l}32- \\
50\end{array}$ & 18 \\
\hline $\begin{array}{l}\text { In charge midwives in the } \\
\text { non-educational hospitals }\end{array}$ & 3 & 5 & $\begin{array}{l}\text { Master degree } \\
\text { and PhD }\end{array}$ & $\begin{array}{l}29- \\
46\end{array}$ & 18 \\
\hline $\begin{array}{l}\text { Head of midwifery } \\
\text { department in non- } \\
\text { governmental universities }\end{array}$ & 1 & 5 & $\begin{array}{l}\text { Master degree } \\
\text { and PhD }\end{array}$ & $\begin{array}{l}28- \\
47\end{array}$ & 14 \\
\hline $\begin{array}{l}\text { Midwives in medical } \\
\text { system with work licenses }\end{array}$ & 4 & 5 & $\begin{array}{l}\text { Master degree } \\
\text { and PhD }\end{array}$ & $\begin{array}{l}30- \\
45\end{array}$ & 13 \\
\hline $\begin{array}{l}\text { Midwives in the } \\
\text { headquarters of the } \\
\text { ministry of health }\end{array}$ & 1 & 5 & Master and $\mathrm{PhD}$ & $\begin{array}{l}30- \\
48\end{array}$ & 17 \\
\hline Midwifery students & 3 & 5 & $\begin{array}{l}\text { The third and } \\
\text { fourth year of } \\
\text { education }\end{array}$ & $\begin{array}{l}20- \\
26\end{array}$ & 3 \\
\hline
\end{tabular}


In this study 259 strategies were proposed by the participants. After elimination of similar cases, this number decreased to 162 strategies. In the next stage, the similar cases were integrated with each other yielding 66 strategies.

The finalized strategies were categorized in eight areas including education, human force, encouragement and support systems, cares and duties of midwives, facilities and equipment, policy making, monitoring and intersectional/ interdisciplinary activities (Fig. 1). Each area is shown with some examples as follows:

\section{Educational promotion and development}

According to the participants' views in different groups, the main concern of the participants was to improve the quality of midwifery care. Developing and improving the educational status of midwifery students and graduates' midwives in order to increase the necessary capabilities and increasing the knowledge recipients of service of their reproductive rights was one of the main concerns of participants. One of the participants said: "Midwifery training programs and residents of gynecology should be regularly reviewed, especially on filed training. So that after graduation they can provide independent, committed and efficient midwifery services."

One of the midwifery board members emphasized on the need to empower faculty members in clinical education and as a way to improve the quality of midwifery services. She said "midwifery faculty members should be selected according to specific and standard criteria, and even if they need, they should pass mandatory skill courses at the beginning of their enrollment, and they pass training periods during their services. Of course, improving the quality of education is very important for midwifery students, but due to the increasing clinical evidence, in-service training of midwives should not be neglected." One of the private sector midwives stated "In order to improve the services of the midwives, or to extend the midwifery license in the maternity wards of training courses, it is possible to make working with a license conditional on passing some skill courses".

This participant even emphasized: "In order to coordinate the health sector with treatment or for proper control of prenatal care, passing some of these courses, even for midwives working in the health sector are required".

Several groups of participants stated that; one of the ways to promote midwifery services is to educate service recipients and educate the community to be aware of the real needs and expectations and fertility rights, increase understanding of midwifery care needs and also be aware of the possibility of choice. Free and informed decision-making of the service recipient based on receiving comprehensive information as well as making the delivery pleasant were emphasized by the participants.

One of the participants in the midwifery service group stated, "We can use a cohesive program, not a oneon-one session, through mass media to promote natural childbirth or teach safe pregnancy issues in premarital education classes." "By educating women and increasing their decision-making skills, and 
perhaps even educating their husbands and families, we can improve the quality of midwifery services they need."

\section{Scope of manpower management}

Participants in this study pointed out strategies that midwifery can achieve the best results from services that are the health of mothers and neonates. One of the midwives in the group of in charge midwives stated that having midwifery supervisor is the way to improve the quality of midwifery services. She said "in the hospital, each profession has a supervisor, therefore, midwives need a supervisor. Because we do not have a supervisor, when it comes to calculate salaries and benefits, midwives are not counted. When the authorities estimate manpower, midwives are not estimated in proportion to the workload. When something wrong happens, there is no professional manager who can support it in a timely manner".

Several participants in the group of midwives in charge in educational and non-educational hospitals also raised this issue regarding the position of midwives. "Midwives in the delivery room and postpartum ward have the greatest role in reducing maternal and neonatal mortality rates, even infection of the baby and morbidity of mothers. Midwives should be a key member of maternal mortality committees, they can comment on process reform".

One of the suggested solutions was the presence of an experiences midwife with work experience in the quality improvement office to do accreditation.

One of the important issues in the discussion of manpower management is providing the necessary manpower to provide midwifery services, so the participants have proposed it as a solution.

One of the participants in the discussion of the staff members' group mentioned this solution: "'" The number of midwives in the hospital are not proportional to the workload of midwives because the recruiting ranks for midwives are not enough. Midwives have to do a lot of work with a small number of staff. For this reason, we are constantly facing a shortage of staff in the midwifery sector, and it is definitely necessary to create a new midwifery recruitment row in order to provide quality services".

\section{Support and incentive systems}

Participants who worked in the maternity wards suggested following solutions: one of the stated: "The midwife perform delivery, not only the delivery, but all care during the labor. When officials want to pay incentives for a natural childbirth, the payment to the midwife is very small, especially in the noneducational hospitals. Authorities should propose methods to motivate midwives. Not only the payment system for midwives should be reformed, but the midwifery payment should be implemented in the same way in all centers".

One of the issues raised by many of participants which can be effective as a supportive strategy was considering of work difficulty of midwives. One of the participants stated: "everyone knows that the delivery room has special condition due to noise pollution, constant contact with blood and discharge during childbirth, and stress caused by the emergency situation of the mother and the baby. Therefore, 
delivery room should be considered as an emergency department, and emergency fees should be given to midwives in delivery rooms.

\section{Limits and competencies of midwifery work in different positions}

One of the participants stated "In a teaching hospital, the job description of a teaching midwifery faculty should be specified and there should be a system for monitoring the performance of the instructor. In fact, the qualification condition should be specified for the instructor. One of the most important topics is the continuous training of clinical skills for physiological delivery without interventions for all those who work in the delivery room."

She also added "The system of registration of births should be reformed. Who hospitalized the patient, who cared, who made the delivery, who performed the control after delivery? Documentation should be organized and the General Directorate of Midwifery should analyze and evaluate them and send to midwives and specialists. The deputy director of treatment should review the statistics, instructions, etc. in order to improve services."

\section{Equipment and facilities}

Participants believed that; to achieve better results in designing educational spaces and fostering creativity, it is necessary to know the different effective dimensions of educational spaces. In this regard, recognizing educational spaces and making them flexible based on student interactions and maximizing environmental capabilities, the possibility of evolutionary flexibility and growth over time will play a significant role in improving the quality of education.

The finalized solutions were classified into eight areas including education, manpower, incentive and support system, midwifery care and duties, equipment and facilities, policy making, monitoring and interdisciplinary activities. Each domain with examples is shown in Table 2. 
Table 2

strategies for promoting midwifery care in Iran in terms of 8 areas from the perspective of midwifery experts $(\mathrm{N}=121)$

\section{Area}

Educational

development and

promotion
University

Paying special attention to the quality of midwifery student' education and selecting their instructors based on specific criteria.

The education of midwifery students should be reviewed so that they are committed and efficient after graduation.

Increasing the training course of midwifery students to 5.5 years

Use of midwives with theoretical and clinical experience and in education of midwifery students.

Upon arrival and during service

Holding a training course on childbirth preparation for midwives in the health centers.

Training of newly arrives personnel

Continuous and codified training for midwives in the maternity ward

Periodic training for midwives of health centers for proper control of mothers of prenatal education.

Educate the community

Using the media to promote natural childbirth and install advertising banners
Educating pregnant mothers in health centers about natural childbirth

Obligation to teach the benefits of natural childbirth in pre marriage counseling classes

Creating a culture about natural childbirth and the complications of cesarean section, especially on television

Manpower management

Creating new positions of employment for midwives

Provide skilled midwifery

Management of midwifery forces
Recruitment based on skills, efficiency and scientific knowledge

Using midwives in clinical fields

Providing license to employ midwives for clinical work 


\section{Area}

Supportive and incentive systems

Payments of natural births to midwives in hospitals

Legal protection of midwives in the private sector

Payment system modification

Increase the difficulty of midwifery job to $100 \%$

Creating motivation by assigning of in charge midwife to the head of delivery ward

Midwives care and duties

Review the list of medications that the midwife can prescribe

Full implementation of the midwives' duties approved in 2009

Equipment and Facilities

Maternity facilities should be re-established

Equipment hospitals with 24-hour physiological delivery wards

Standardization of delivery wards in all hospitals

Modification of physical environment of hospitals for rapid access of clients in time of emergencies

Policy making

Determining the appropriate position of midwives in the family physician and referral program

Hospitals should not be self-government

Considering the new policy of increasing of Iran's population using natural birth

Supervision

Creation of punishment tools for specialists who perform elective or un-necessary cesarean

Establish a strong system to monitor cesarean section indications

Supervision on implementation of rules issued about midwifery

Interdisciplinary activities

Increase the relationship between midwives and gynecologists

Increase interaction between private universities and ministry of health

Holding periodic symposium session between midwives of the private and governmental universities.

\section{Discussion}


This study aimed to provide strategies for improving the quality of midwifery care and developing midwife-centered care in Iran. The finalized strategies were categorized in eight areas including education, human force, encouragement and support systems, cares and duties of midwives, facilities and equipment, policy making, monitoring and intersectional/ interdisciplinary activities.

As far as strategies for improving midwifery services are concerned, WHO has introduced a nineparagraph toolbox/directory in 2010 , with each paragraph dealing with a certain aspect of improving the role of midwifery in caring for mothers and babies. The first section presents an overview of the position and the general role of midwifery in improving pregnancy, delivery, and post-delivery care and teamwork of midwives with other gynecologists. In the second section, the rules and regulations about the improvement of midwifery care in each country are emphasized. In the third section, adjustment, implementation, and monitoring of the midwifery care standards are discussed. The fourth section addresses the skills and abilities of midwives. The fifth section deals with training and educating midwives and the quality of these trainings.

The sixth section is concerned with midwifery instructors and academic staff who have to play a fundamental role in empowering midwives in addition to their own abilities. In the seventh section, the guiding and directing of midwives discussed, stating that in the case of appropriate guiding and directing of midwives, they can provide high quality care. The eighth section devoted to the continuous discussion of training and empowering midwives after employment and while performing their duties. In the last section (Sect. 9), creating and developing skills in midwives is discussed, emphasizing the skills that can empower midwives to improve the care of mothers and babies (21).

Another comprehensive report has been issued by the Involvement and Participation Association (IPA) and the Royal College of Midwives in the UK with respect to strategies for improving midwife-based cares and the role of midwives. The most important strategies provided in the report includes supporting the midwifery leaders at all organizations levels, performing team works and creating the atmosphere of learning from each other, integrating the midwifery cares with society's plans and conditions, and designing and presenting available cares based on the individual conditions of the people (22). Our findings are similar to the strategies mentioned by the WHO, IPA, and the Royal College of midwives in England. Thus, it seems that the strategies presented in this study have high reliability and validity to be used in plans and decisions by managers and policymakers.

Enhancement of the quality of midwifery education was among the most important issues emphasized by most of the participants regarding the development and improvement of midwife-based care. During recent years, some studies conducted in Iran have shown that midwifery education is faced with many problems because the midwifery student is not allowed to gain experience herself in educational hospitals. Therefore, midwifery students are sometimes unable to learn properly, because of the involvement of gynecologists in their training. However, when midwifery students receive training in nonuniversity hospitals and are trained by midwifery academic staff, this training is much more effective. 
In fact, in spite of the lack of welfare facilities for non- medical students in Iran's universities, still midwifery education has an acceptable level (23-24). The quality of midwifery education has a deep influence on the presentation of clinical midwifery skills. The graduated midwives should have obtained the minimum clinical and professional skills to perform midwifery duties in order to provide and improve the care for mothers and babies and ultimately enhance the health of the community (25).

To improve their quality, educational plans must be evaluated at certain junctures. One of the fundamental strategies to identify the quality of education is assessing the implemented plan as well as its evaluation based on the acceptable standards that are the significant stimulus for improving and elevating education quality and expanding equal opportunities for research and development of education among all students in Iranian universities. Educational assessment involves measuring the performance of learners and comparing the results obtained from the predefined educational purposes in order to make a decision on whether and how much the educational activities and learning endeavors of the students have led to the desired results (26).

Training midwives and increasing their awareness, were mentioned repeatedly by the participants throughout discussion in this study.

In a joint project with the Institution of Health Equality (IHE), the National Health Service (NHS) of England published a joint report to investigate the strategies of influencing the health system and health inequalities in 2018. In this report, some strategies are explained by the staff and policymakers of the health system that can reduce the inequalities. These recommendations are presented in order for the health system to focus on the social factors influencing the health and in order to decrease health inequality and they include certain measures that can be considered by the health section staff as a part of their work activity.

The first and one of the most important parts of these strategies are training the people and empowering them. In this report, it has been strongly emphasized on the pieces of trainings provided by midwives and educational plans for women and their husbands during pregnancy, post-partum consultation about baby care and lactation, training parents about the early years of the children's life, consultation for early detection of postpartum blues, and providing other relevant and professional pieces of trainings (27).

According to the definition of midwifery, the important duty of the midwife is counselling and health training for not only pregnant women and families but for the whole society as well. Moreover, it has been pointed out that the work of midwives should include education on the pregnancy period, and preparation of parents for accepting their parental duties, and it must be extended to family planning and caring of children and some cases of women's gynecological conditions (28). According to the "Midwifery 2020" programme, published by nursing organizations of four countries of England, Northern Ireland, Wales, and Scotland, one of the necessities and fundamental strategies for effectiveness of the midwifery services is empowering midwives to be capable of communicating with people and also the advisory role of the midwife. In this report, the authors maintain that due to the wider relationship of midwives with the people and considering the wide range of services that midwives are able to provide from pre-marriage 
issues to raising children, they are required to have a wide range of capabilities; and this needs providing comprehensive training for the midwives (29).

The most important strategies recommended by the participants in the present study in terms of human resources were mostly related to employment and increase of midwifery human resources. In this respect, the head of the midwifery association pointed out that according to the law approved by the Ministry of Health, there must be twelve midwives for every 1000 live births in hospitals, but at the present time, only 8-9 midwives are available for every 1000 live births in Iranian hospitals. It is worth mentioning that of the 8000 employed midwives, 2700 are provisionally employed, and after two years, most of them become unemployed (30). As far as the employment of midwives is concerned, the need for midwifery care and services is on the rise and more midwives should be employed, considering the implementation of the urban family doctor plan in Iran and the fact that vaginal delivery is free of charge in governmental hospitals.

Another topic mentioned by most of the participants in the present study was related to the encouragement and motivating of the midwives. The payment of midwives was among the most important issues mentioned by the participants. They believed that without good payments for the midwifery services, they would not have sufficient motivation and inclination to provide high- quality services. Previous studies also mentioned the significance and place of the appropriate payment for midwives in providing appropriate services by this group of health care providers (31-32). The performance-based payment was another topic that most of the participants mentioned in this study. They believed that; most the midwives are not satisfied with their salary in hospitals and health care networks.

In this study, the head of midwifery scientific association stated that, more than 450,000 normal deliveries were attended by the midwives last year, but only 15 percent of the delivery tariff was paid to them. She also added, "the delivery tariff deserves to be fairly distributed, yet not only do we observe that no increase has been considered in the payments of midwives, but also their predefined rights have been ignored". Almost all fees are paid to on-call obstetricians, not to the midwives who care for mothers from the first stage of labor to the end. Since workplace discrimination and injustice disappoint the staff and reduce their motivation. Accurate and fair systems should be designed and implemented. Because midwifery is a very sensible practice, payment is more sensitive and significant, too.

In this study, many strategies mentioned by the participants were related to the equipment and facilities of hospitals and maternity wards. The results of the previous studies in this field in Iran also indicated that physical space and facilities of the maternity wards in hospitals are not very satisfying because all women, whether with high or low risk pregnancies, receive the same medical oriented care model offered by obstetricians, exposing them to unnecessary intervention and bringing about possibility of cesarean Sect. (33-34). Sanitation and provision of an appropriate environment for normal delivery can be influential in the satisfaction of mothers and consequently in the delivery pattern. Therefore, alleviating 
shortages related to the physical space and facilities of the delivery wards of paramount importance, and it is expected that this achieved through implementing the health developmental plan (36).

Determining the appropriate position of midwife in the family doctor system and referral system was among the significant discussions repeatedly mentioned by the participants in the present study and this issue was categorized in the area of the policymaking strategies. Several studies have been conducted in Iran on the assessment of the performance of family doctor and referral system (37). The results of most of these studies indicate many weaknesses and problems in the implementation of the family doctor plan and the referral system.

In the present study, one of the strategies mentioned by the participants in line with the development of midwife-based care was the presence of midwives and their bold and predefined role in the family doctor team. In this regard, some of the participants were of the opinion that midwives should have a bold and executive role from the pre-marriage stages until the raising of the children and this role even continue to the middle age.

In the study of Lotfi et al conducted with the aim of presenting strategies to reduce the cesarean rate in Iran, the revisiting the roles of midwives and determining proper ones for them were emphasized. Moreover, researchers put emphasis on the visiting of pregnant women and referring them by the midwives in the first line of care (37).

In the present study, most of the participants pointed out that the obstetricians (gynecologists) often tend to perform cesarean and do not pay attention to cesarean indications. They believed that according to the gynecologists' opinion, normal delivery is very time consuming while cesarean section takes them only one hour to perform, so the strategies the participants proposed included imposing strict and efficient punishment and monitoring system to control the performance of the gynecologists in hospitals. Faraji et al (38), found that in $70 \%$ of cases, gynecologist played the main role in the high cesarean section rate. Moreover, Signorelli et al. (53) in Italy also found that the gynecologists played a fundamental role in choosing the mode of delivery. Another study by Menacker et al. (39), attributed the increase in the cesarean rate among women with no indication for cesarean was the tendencies and the judgment of doctors. Perhaps the high tariffs of cesarean surgery compared with the normal delivery subconsciously motivate the doctors for performing more cesarean operations. In this regard, implementation of the plan of actualization of hospital services tariffs in Iran can be significantly influential.

Moreover, the development of self-control and monitoring tools and methods in this field could be useful.

As far as interdisciplinary teamwork was concerned, the improvement of the collaboration between midwives and gynecologists was a topic that frequently mentioned by the participants. In the study of Heatly \& Kruske, the interdisciplinary collaboration in maternal care has been defined as "a reflective and dynamic process that involves the mother and baby cares professionals in several professions and with the participation of the same mother to generate high quality care. It shares the accountability and responsibility in terms of appropriate levels of the involvement of a professional with the mother during 
the total period of childbirth. All involved institutions use the observance, understanding, and development of an approach for their performance that uses the knowledge and different professions as the mother needs (40). In the study of Lotfi et al, interdisciplinary collaboration is emphasized to have a role in the reduction of cesarean rate (37). The American College of Gynecology and Midwifery has also specified some objectives in relation to the safety of patients. One of these objectives is the commitment to the culture of patient safety through daily practical teamwork, communications, collaboration, and strong leadership about the service providers (40). The effective collaboration among the professional groups has increasingly been the focus of attention as the fundamental element in safety and good quality of health care. This is especially significant in the context of maternal care, where women have the experience of delivery (41).

According to the results of some recent studies, the most important obstacles of teamwork are as follows: lack of a clear definition for individual's duties, weak management, inconsistent communication, the presence of a hierarchical relationship in wards, insufficient skill and knowledge, and inappropriate division of responsibilities (42-43). In order to reduce the adverse effects arising from interdisciplinary conflicts on the quality and safety of providing health services, especially the sensitive and emergency services like delivery cares, planning and implementing effective interventions in this field must be prioritized (44).

The main limitation of the current study is the nonparticipation of high-ranked authorities and policymakers of the Ministry of Health and Medical Education.

\section{Conclusion}

The results of this study showed that in order to improve midwifery care, emphasis should be put on the quality and quantity of midwifery education, training individuals and informing them, and increasing midwifery human resources through employment, as the most important factors. Furthermore, insurance support, encouragement, supporting and motivating the midwives, enhancing and improving the facilities and providing hospitals and maternity wards with cutting-edge equipment, promoting and reinforcing the position of midwives in the family doctor system, and using a referral system have been mentioned by the participants as strategies for improving midwifery care. Finally, establishing an efficient and powerful monitoring system to control the performance of gynecologists and midwives, increasing the collaborative practice of midwives and gynecologists, promoting team working with respect to midwifery care are strategies to improve the midwifery service in Iran.

\section{Abbreviations}

WHO: World Health Organization

IPA: Involvement and Participation Association

IHE: Institution of Health Equality 


\section{Declarations}

Ethics approval and consent to participate: All participants provided written informed consent before data collection

Consent for publication: NA

Availability of data and materials: Data of this study will be available upon the request from the corresponding author.

Competing interests: Authors do not have any competing interest.

Funding: NA

Authors' contributions: SK, FB, PA, ZMK, and SSH contributed to the conception of this study. SK, FB, ZMK, and SSH collected data. SK and PA wrote and finalized the study. All authors read and approved the content of the study.

Acknowledgements: The authors would like to sincerely thank the participants who so generously gave their time to participate in the interviews and share their experiences.

\section{References}

1. Cunningham F, Leveno K, Bloom S, Fauser J, Zwirner M. Williams Obstetrics. New York: GrawHill.Day-Stirk, 2018

2. World Health Organization. Maternal, newborn, child and adolescent health. available at: https://www.who.int/maternal_child_adolescent/documents/mothers/en/. Accessed date: 28 August 2020.

3. Centers for Disease Control and Prevention. Recommendations to improve preconception health and health care-United States: A report of the CDC/ATSDR Preconception Care Work Group and the Select Panel on Preconception Care. MMWR. 2006;55(RR-06):1-23.

4. Tuncalp Ö, Were WM, MacLennan C, Oladapo OT, Gulmezoglu AM, Bahl R, et al, Quality of care for pregnant women and newborns - the WHO vision. Br J Obstet Gynaecol 2015;122:1045-1049.

5. World Health Organization. Maternal, newborn, child and adolescent health, The case for midwifery. https://www.who.int/maternal_child_adolescent/topics/quality-of-care/midwifery/case-formidwifery/en/. Accessed date: 25 June 2020.

6. Homer, CS, Friberg, IK, Dias, MA et al. "The projected effect of scaling up midwifery". Lancet. 2014;384: 1146-1157 
7. World Health Organization. Investment in midwifery can save millions of lives of women and newborns Joint news release WHO, UNFPA, International Confederation of Midwives. Available at: https://www.who.int/mediacentre/news/releases/2014/investment-midwifery/en/.Accessed date: 25 June 2020.

8. Bulletin of the World Health Organization 2013;91:804-805. doi: http://dx.doi.org/10.2471/BLT.13.021113

9. World Health Organization. Maternal mortality. Available at: https://www.who.int/news-room/factsheets/detail/maternal-mortality. Accessed date: 28 August 2020.

10. Austin M, Kildea S, Sullivan E. Maternal mortality and psychiatric morbidity in the perinatal period: challenges and opportunities for prevention in the Australian setting. Med J Aust 2007; 186 (7): 364367. || doi: 10.5694/j.1326-5377.2007.tb00940.x

11. Fontein-Kuipers Yvonne, Groot Rosa de, van Staa AnneLoes. Woman-centered care 2.0: Bringing the concept into focus. Eur J Midwifery 2018;2(May):5. DOI: https://doi.org/10.18332/ejm/91492

12. Merz WM, Tascon-Padron L, Puth MT, Heep A, Tietjen SL, Schmid M, Gembruch U. Maternal and neonatal outcome of births planned in alongside midwifery units: a cohort study from a tertiary center in Germany. BMC Pregnancy Childbirth. 2020; 20: 267. doi: 10.1186/s12884-020-02962-4

13. AZAMI-AGHDASH S, GHOJAZADEH M, DEHDILANI N, MOHAMMADI M, ASL AMIN ABAD R. Prevalence and Causes of Cesarean Section in Iran: Systematic Review and Meta-Analysis. Iran J Public Health. 2014 May; 43(5): 545-555.

14. Araban M, Karimy M, Tavousi M, Shamsi M, Niakan Kalhori S, Khazaiyan S. Quality of Midwifery Care Provided to Women Admitted for Delivery in Selected Hospitals of Yazd. J. Nurs. Midwifery Q. Shaheed Beheshti Univ. Med. Sci. Health Serv, 2013; 81(23), 19-26.

15. Likis FE. The Lancet series on midwifery: a momentous opportunity to improve maternal and newborn health. J Midwifery Womens Health, 2014; 59(5), 477-478.

16. ten Hoope-Bender P, de Bernis L, Campbell J, Downe S, Fauveau V, Fogstad H, Renfrew M J. Improvement of maternal and newborn health through midwifery. The Lancet, 2014;384(9949), 12261235.

17. Mortensen B, Lieng M, Diep LM, Lukasse M, Atieh K, Fosse E. Improving Maternal and Neonatal Health by a Midwife-led Continuity Model of Care - An Observational Study in One Governmental Hospital in Palestine. Lancet EClinicalMedicine. 2019; 10: 84-91.

18. Wernham E, Gurney J, Stanley J, Ellison-Loschmann L, Sarfati D. A Comparison of Midwife-Led and Medical-Led Models of Care and Their Relationship to Adverse Fetal and Neonatal Outcomes: A Retrospective Cohort Study in New Zealand. Plos Medicine. 2016; https://doi.org/10.1371/journal.pmed.1002134

19. Grbich C. Qualitative data analysis: An introduction: Thousand Oaks. CA: Sage. Gross, M. (2007). [WHO wants to lower maternal mortality. CMAJ, 2007; 174(4), 455-460.

20. Pope C, Ziebland S, Mays N. Analysing qualitative data. BMJ, 2000; 320(7227), 114-116. 
21. World Health Organization. Strengthening Midwifery Toolkit. Performance-based pay plan is get disillusioned of midwives. Retrieved from: http://www.

https://www.who.int/maternal_child_adolescent/documents/strenthening_midwifery_toolkit/en/. 2011

22. Jameson H. Innovation and Improvement in Midwifery Services. UK: The Royal College of Midwives and Involvement and Participation Association (IPA), 2015.

23. Omidvar S, Salmalian H, Azimi H. Evaluation of clinical education problems from the senior midwifery students' point of view in Babol University of Medical Sciences. Iranian Journal of Education in Medical Sciences, 2005; 14, 77-78. (Persian).

24. Yaghubi T, Salemeh F, Golmohammadi F, Vaziri, F. Evaluation of clinical education problems and from the Nursing students' point of view in Mazandaran University of Medical Sciences. Iranian Journal of Education in Medical Sciences, 2005; 14,114-115. (Persian).

25. Sandall J, Soltani H, Gates S, Shennan A, Devane D. Midwife-led continuity models of care compared with other models of care for women during pregnancy, birth and early parenting. Cochrane Database of Systematic Reviews 2016, Issue 4. Art. No.: CD004667. DOI:

10.1002/14651858.CD004667.pub5

26. Allahdadyan M. Appropriate standards recommend by nursing and midwifery council borrowed from international standards. Iran J Med Educ, 2008; 8(1), 15-22.

27. UCL INSTITUTE OF HEALTH EQUITY. Reducing Health Inequalities through new models of care: A resource new care models. 2019

28. Kennedy. Midwifery 2020 Programme London. Jill Rogers Associates. Department of Health and Social Care, 2010.

29. Midwifery 2020 Programme Measuring Quality Workstream Final Report. Available at: https://www.nes.scot.nhs.uk/media/1891400/measuring_quality.pdf

30. Firouznia R, Dargahi H, Koshki TJ, Khaledian Z. Challenges of Iranian Maternal Health Program from Midwives' Perspectives: A Qualitative Study. JUNDISHAPUR JOURNAL OF HEALTH SCIENCES. 2019; 11(3): e92354. DOI : 10.5812/jjhs.92354

31. Ikegami N. The Japanese Health Care System-Achieving Equity and Containing Costs Through a Single Payment System. Am Heart J, 2007; 5(1), 27-31.

32. Ruhago GM, Mujinja PG, Norheim OF. Equity implications of coverage and use of insecticide treated nets distributed for free or with co-payment in two districts in Tanzania: A cross-sectional comparative household survey. Int J Equity Health, 2011; 10(1), 29.

33. Alidosti M, Tahmasebi M, Raeisi M. Evaluating the women's satisfaction of Hajar hospital services after the delivery. J Clin Nurs Midwife, 2013; 2(1), 1-8.

34. Mesgarzade M, Baghaei R, Ebrahimi M, Orujlu S. Survuy of mother's satisfaction from provided care in delivery unit in the Khoy Qamar Bani Hashem hospital in 2012. J. Urmia Nurs. Midwifery Fac, 2014; 12(10), 919-925. 
35. Gholami-Taramsari M. Ten-Year Evaluation of Maternal Mortalities in Kohgiluyeh and Boyerahmad Province. Knowledge \& Health, 2008; 3(2)3: 33-37.

36. Jannati A, Maleki M, Gholizade M, Narimani M, Vakeli S. Assessing the strengths \& weaknesses of family physician program. Knowledge and Health. 2010; 4(4): 38-43.

37. Lotfi R, Tehrani FR, Dovom MR, Torkestani F, Abedini M, Sajedinejad S. Development of strategies to reduce cesarean delivery rates in Iran 2012-2014: A mixed methods study. IJPM, 2014; 5(12), 1552.

38. Faraji Dor Khaneh R, Zahiri S, Farjad B. Knowledge and Attitudes of pregnant women to normal delivery methods. J Guilan Univ Med Sci, 2003; 12(46), 69-75.

39. Menacker F, Declercq E, Macdorman MF. Cesarean delivery: background, trends, and epidemiology. Seminars in Perinatology, 2006; 30(5):235-241).

40. CoQlaPS, A. ACOG committee opinion: Patient safety in obstetrics and gynecology. Int J Gynecol Obstet, 2004; 121-123.

41. Downe S. Creating a Collaborative Culture in Maternity Care. J Midwifery Womens Health, 2010; 55(3), 250-254.

42. Chakraborti $C$, Boonyasai R, Wright $S$, Kern D. A systematic review of teamwork training interventions in medical student and resident education. J Gen Intern Med, 2008; 23(6), 846-853.

43. Eldar R, Marincek C, Kullmann L. Need for rehabilitation teamwork training in Europe. Croat Med J, 2009; 49(3), 352-357.

44. Reiger KM, Lane KL. Working together: collaboration between midwives and doctors in public hospitals. Australian Health Review, 2009; 33(2), 315-324.

\section{Figures}




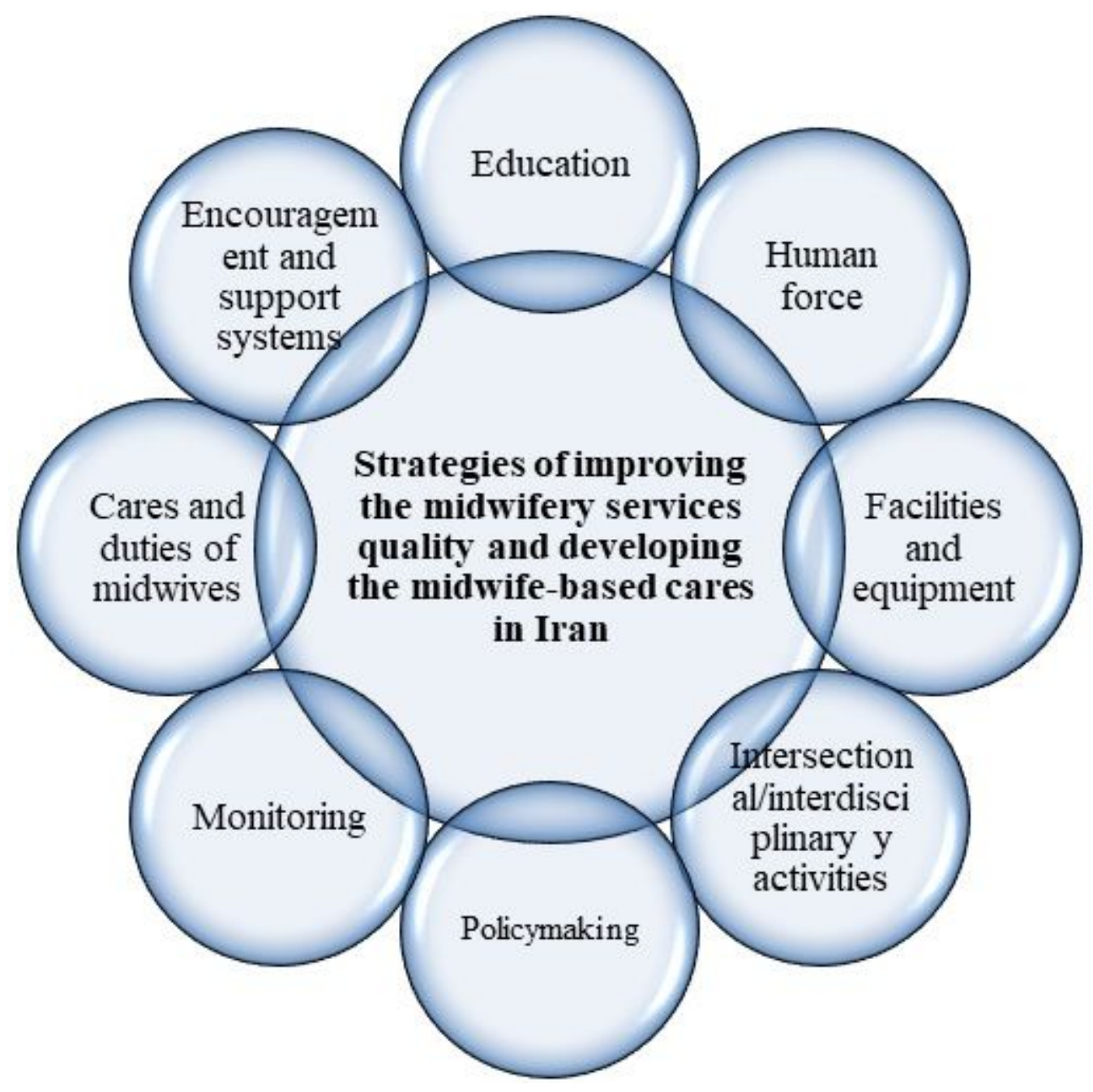

Figure 1

The general areas of strategies of improving the midwifery-based cares in Iran from the viewpoint of midwifery scholars of Iran 